\title{
Influence of Harvest Time on Biologically Active Compounds and the Antioxidant Activity in Leaves of Mulberry Grown in Lithuania
}

\author{
Dovilè LEVICKIENE ${ }^{1 *}$, Elvyra JARIENE ${ }^{1}$, Marek GAJEWSKI ${ }^{2}$, \\ Honorata DANILČENKON ${ }^{1}$, Nijolè VAITKEVIČIENE ${ }^{1}$, \\ Jarosław L. PRZYBYE², Monika SITAREK ${ }^{2}$ \\ ${ }^{1}$ Aleksandras Stulginskis University, Agronomy Faculty, Agriculture and Food Sciences Institute, Studentu str. 11, \\ Akademija,LT-53361Kauno district,Lithuania; dlnlulgl@gmail.com (“correspondingauthor); elvyra.jariene@asu.lt; \\ honorata.danilcenko@asu.lt;nijole.vaitkeviciene2@gmail.com; \\ ${ }^{2}$ Warsaw University of Life Sciences - SGGW, Department of Vegetable and Medicinal Plants, Nowoursynowska 166, 02-787 Warszawa, \\ Poland; marek_gajewski@sggw.pl;jaroslaw_przybyl@sggw.pl;monika_sitarek@sggw.pl
}

\begin{abstract}
The aim of this study was to establish the influence of harvest time on the contents of flavonoid compounds (rutin, isoquercetin, nicotiflorin, and astragalin) and chlorogenic acid, as well as the antiradical activity in white mulberry (Morus alba L.) leaves grown in Lithuania. Mulberry leaves contain a wide range of bioactive compounds, such as flavonoids and phenolic acids, which are responsible for beneficial effects on human health. Leaves from two mulberry cultivars were collected from July to September in 2015-2016. Quantitative determinations of four flavonoids and chlorogenic acid were conducted by HPLC method and antiradical activity using the 2.2-Diphenyl-1-picrylhydrazyl (DPPH) radical scavenging method. The results showed that the total flavonoid contents of mulberry leaves in the two cultivars ranged from 921.92 to $1512.02 \mathrm{mg} 100$ $\mathrm{g}^{-1}$ (dry matter). The highest accumulated rutin, nicotiflorin, and chlorogenic acid contents and the greatest antioxidant activity were found in the leaves of 'Plodovaja 3 '. The bioactive compounds in the leaves of the mulberry cultivars varied over a period of time, where 'Turchanka' and 'Plodovaja 3' accumulated the highest total flavonoid contents in September and August, respectively. In both cultivars, the antiradical activity was highest in September. There were a very strong positive correlations between the antiradical activity as determined using the DPPH method and the chlorogenic acid contents $(\mathrm{r}=$ $0.887, p<0.05)$ and the isoquercetin contents $(r=0.848, p<0.05)$.
\end{abstract}

Keywords: chlorogenic acids, flavonoids, harvest time, Morus alba

\section{Introduction}

Over the past decade, the interest in biologically active compounds from plants has increased greatly. Most of these compounds are of nutritional and pharmacological interest and the quality of the raw materials has been determined (Katsube et al., 2006; Chauhan et al., 2015). The mulberry tree (Morus alba L.) is a member of the family Moraceae and genus Morus, which can grow under various climatic conditions (i.e., tropical, subtropical, and temperate) (Memon et al., 2010). Most parts of the mulberry are used in the food industry, including the leaves in teas, infusions, and as vegetables (Sývacý and Semen, 2004; Paredes-López et al., 2010; Łochyńska, 2015). It has been reported that mulberry leaves are rich in proteins, carbohydrates, fats, mineral elements, and vitamins (Srivastava et al., 2006; Butt et al., 2008; Adeduntan and Oyerinde, 2009).

Mulberry leaves have beneficial pharmacological effects, such as influencing the hypoglycemia activity and antioxidant capacity, reducing blood pressure, anti-aging effects, enhancing immunity, and anticancer effects (Chan et al., 2016; Jeszka-Skowron et al., 2017). These beneficial effects can be attributed to the bioactive compounds present in mulberry leaves, especially flavonoids and chlorogenic acid (Radojkovic et al., 2012; Sugiyama et al., 2017).

Flavonoids comprise the largest and most diverse group of phenolic compounds in plants. The recent interest in these compounds has been stimulated by potential health benefits due to the antioxidant activities of these 
432

compounds (Zhishen et al., 1999; Arct and Pytkowska, 2008). The main types of flavonoids in mulberry leaves are rutin (quercetin 3-O-rutinoside), isoquercetin (quercetin 3-O-glucoside), astragalin (kaempferol 3-O-glucoside), and quercetin 3-(6malonylglucoside) (Lee et al., 2007; Kobayashi et al., 2015). Phenolic acids are known to possess significant biological activities, and the predominant phenolic acid in mulberry leaves is chlorogenic acid, which comprises a significant fraction of the total dietary intake of phenols in the daily human diet. Phenolic acids have some notable biomedical or pharmacological properties (Katsube et al., 2006). Thus, mulberry leaves are attracting much interest as promising dietary sources for functional foods with health benefits (Lee and Choi, 2012).

The nutritional value and antioxidant activities of mulberry leaves depend on many factors, such as the cultivar, environmental conditions, type of field, leaf age, time of harvesting, fertilizers, and mode of food administration (Matei et al., 2006; Sugiyama et al., 2016a, 2016b). Quality characteristics of mulberry leaves grown in Lithuania have been poorly investigated. Lithuanian growers also lack knowledge of how to harvest and use this raw material in a rational way. Therefore, in the present study, we determined the impact of the harvest time on the flavonoid (rutin, isoquercetin, nicotiflorin, and astragalin) and chlorogenic acid contents, as well as the antioxidant activity of leaves from two mulberry cultivars.

\section{Materials and Methods}

\section{Field experiment}

The field experiment was conducted in 2015-2016 on an organic farm in the Kaunas district of Lithuania $\left(54^{\circ} 53^{\prime} 50^{\prime \prime} \mathrm{N}\right.$; $\left.23^{\circ} 53^{\prime} 10^{\prime \prime} \mathrm{E}\right)$. The soil in the experimental field was characterized by close to neutral acidity $\left(\mathrm{pH}_{\mathrm{KCl}}=6.37-6.81\right)$, medium to high potassium status $\left(\mathrm{K}_{2} \mathrm{O}=189.6-199.2 \mathrm{mg}\right.$ $\left.\mathrm{kg}^{-1}\right)$, medium to above medium phosphorus status $\left(\mathrm{P}_{2} \mathrm{O}_{5}=\right.$ 122.59-137.05 $\left.\mathrm{mg} \mathrm{kg}^{-1}\right)$, and the total nitrogen content was $0.151-0.226 \%$.

\section{Mulberry leafsamples}

White mulberry cultivars 'Plodovaja 3' and 'Turchanka', originating from Ukraine, were grown on an organic farm in Lithuania. Leaves from each mulberry cultivar were harvested once a month over three consecutive months during the growing period (June, August, and September) in 2015-2016. Mulberry leaves were collected, lyophilized using a FreezeDrying Plant Sublimator $3 \times 4 \times 5$ (ZIRBUS Technology $\mathrm{GmbH}$, Bad Grund, Germany), and finally ground to a fine powder in a laboratory mill (Grindomix GM 200, Retsch $\mathrm{GmbH}$, Haan, Germany). Chemical analyses of mulberry leaves were conducted in the laboratory of the Department of Vegetable and Medicinal Plants, Warsaw University of Life Sciences - SGGW (Poland).

\section{Mulberry leaf extracts}

The powdered leaf samples $(2 \mathrm{~g})$ were extracted with 15 $\mathrm{mL}$ of methanol (Sigma-Aldrich, Poznan, Poland) for $30 \mathrm{~min}$ at $40{ }^{\circ} \mathrm{C}$ in sonication bath (Sonic 6, Polsonic, Warsaw, Poland). The extracts obtained were allowed to stand for $48 \mathrm{~h}$ at $5^{\circ} \mathrm{C}$, filtered through a filter paper and filled up to $25 \mathrm{~mL}$ with methanol at room temperature. Before HPLC analysis so prepared extracts were filtered with a Supelco Iso-Disc ' Syringe Tip Filter Unit containing a PTFE membrane (diameter $=25$ $\mathrm{mm}$, pore size $=0.20 \mu \mathrm{m})$ into amber glass vials.

\section{Determination of four flavonoids and chlorogenic acid by HPLC}

Standards were purchased from ChromaDex (Irvine, USA) and dissolved separately with methanol in $10 \mathrm{~mL}$ volumetric flasks according to the ChromaDex's Tech Tip 0003: Reference Standard Recovery and Dilution, and used as standard stock solutions. Additional calibration levels (working solutions) were prepared by diluting 10, 50, 100, 200, 500, and $1000 \mu \mathrm{L}$ of the standard solutions with methanol in $10 \mathrm{~mL}$ volumetric flasks. The working solutions were injected $(1 \mu \mathrm{L})$ into a column with six replicates $(n=6)$ using an auto-sampler (SIL-20AC HT, Shimadzu, Kyoto, Japan) to generate a sixpoint calibration curve with LCsolution 1.21 SP1 chromatography software. Standard curve parameters were calculated with Microsoft Excel 14. The signal-to-noise (S/N) ratio approach was used to determined LOD $(\mathrm{S} / \mathrm{N}=3: 1)$ and LOQ $(S / N=10: 1)$. A peak table and UV-spectra library (190-450 nm) were also created for individual compounds.

The analyses were performed using a Shimadzu Prominence chromatograph (Shimadzu, Kyoto, Japan) equipped with an auto-sampler (SIL-20AC HT), photodiode array detector (SPD-M20A), and LCsolution 1.21 SP1 chromatography software. Separations were achieved using a $100 \mathrm{~mm} \times 4.60 \mathrm{~mm} \mathrm{C18}$ reversed-phase with core-shell technology Kinetex $2.6 \mu \mathrm{m}$ column (Phenomenex, USA). A binary gradient comprising mobile phase A (deionized water Cobrabid Aqua, Warsaw, Poland) adjusted to $\mathrm{pH} 2$ with phosphoric acid (Sigma-Aldrich, Poznan, Poland) and B (ACN (Sigma-Aldrich, Poznan, Poland)) was used as follows: $0 \mathrm{~min}=12.5 \% \mathrm{~B} ; 4.0 \mathrm{~min}=23 \% \mathrm{~B} ; 6.0 \mathrm{~min}=60 \% \mathrm{~B} ; 6.1 \mathrm{~min}$ $=12.5 \% \mathrm{~B} ; 10 \mathrm{~min}=$ stop. The HPLC conditions were as follows: flow rate $=1.5 \mathrm{~mL} \mathrm{~min}{ }^{-1}$, oven temperature $=40^{\circ} \mathrm{C}$, injection volume $=1 \mu \mathrm{L}$. Analytical data were recorded at wavelengths of: $255 \mathrm{~nm}$ for quercetin 3-O-rutinoside (rutoside), quercetin 3-O-glucoside (isoquercetin), and kaempferol-3-O-rutinoside (nicotiflorin); $265 \mathrm{~nm}$ for kaempferol 3-O-glucoside (astragalin); and $325 \mathrm{~nm}$ for 3-Ocaffeoylquinic acid (chlorogenic acid). The contents of the determined compounds were calculated as mg per $100 \mathrm{~g}$ of dry matter (DM) (Parejo et al., 2004).

Determination of antiradical activity using the 2,2-Diphenyl1-picrylhydrazyl (DPPH) radical scavenging method

The antiradical activity of aqueous extracts was determined as the Trolox (( \pm$)-6$-Hydroxy-2,5,7,8-tetramethylchromane-2carboxylic acid, Sigma-Aldrich, Poznan, Poland) equivalent antiradical capacity (TEAC) using the DPPH (2,2-Diphenyl1-picrylhydrazyl, Sigma Aldrich, Poznan, Poland) radical scavenging method. The TEAC assay with DPPH radicals was conducted as described by Yen and Chen (1995). All determinations were performed in triplicate. TEAC values were calculated and expressed as $\mu \mathrm{mol}$ of Trolox equivalents (TE) per $1 \mathrm{gDM}$.

\section{Statistical analysis}

Significant differences were determined by analysis of 
variance (ANOVA) using the software package STATISTIKA (STATISTICA 7). Arithmetical averages of the experimental data were calculated. Significant differences between means were estimated using Fisher's LSD test $(p<$ $0.05)$. Correlation regression analysis was performed to determine the nature and strength of correlations between variables.

\section{Results and Discussion}

\section{Flavonoids}

Flavonoids are the most common group of phenolic compounds in the human diet, and plant flavonoids are an important part of the diet because of their effects on human nutrition (Zhishen et al., 1999). Flavonol glucosides in mulberry leaves, including rutin, isoquercetin, astragalin, quercetin 3-(6-acetylglucoside), and kaempferol 3-(6acetylglucoside), have been reported as antioxidants (Matsuoka et al., 1994).

We found that the flavonoid composition of mulberry leaves was influenced by the stage of maturity and cultivar. The total flavonoid (rutin, isoquercetin, nicotiflorin, and astragalin) contents of leaves from the two mulberry cultivars harvested

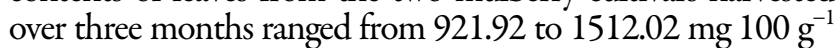
DM (Table 1). The total flavonoid content was higher (1128.89 mg $100 \mathrm{~g}^{-1} \mathrm{DM}$ ) in 'Turchanka' leaves during September compared with other months. However, the highest flavonoid content (1512.02 mg $\left.100 \mathrm{~g}^{-1} \mathrm{DM}\right)$ in 'Plodovaja 3' leaves occurred during August. Maybe these differences between the cultivars are associated with a genetic effect of cultivar. Zou et al. (2012) reported that genotype and growing environment can affect phytochemical production in an interactive manner. Since all the samples were collected from the same orchard, the differences could not be ascribed to growing location, environment or agricultural practice. Thus, only the cultivar difference had an impact on the phenolic content and antioxidant activity, rather than the growing environment.

Jia et al. (1999) also found that the flavonoid contents of mulberry leaves collected in spring and autumn were different. These results indicate that mulberry leaves could be an important source of flavonoids.
Rutin (quercetin-3-O-rutinoside) is a well-known antioxidant and a natural compound with a wide range of medicinal properties (Choi et al., 2009). Guan et al. (2006) indicated that mulberry leaves harvested in autumn would exert larger bio-efficacy than those harvested in summer, probably because of the higher rutin content of the former.

Nevertheless, our results indicate that mulberry leaves are a good source of rutin. We aimed to determine the mulberry cultivar that provided the richest source of rutin depending on the harvest time. Both cultivars were rich in rutin, especially the leaves harvested in July. The amount of rutin was significantly higher in 'Plodovaja 3' leaves (601.41 mg $100 \mathrm{~g}^{-1}$ DM; Table 1) compared with that in 'Turchanka' leaves $\left(337.79 \mathrm{mg}^{100 \mathrm{~g}^{-1}}\right.$ DM). A similar result was reported by Katsube et al. (2006), he found that rutin content of mulberry leaves collected in June were $573 \mathrm{mg} / 100 \mathrm{~g}$ of DM. Our results indicate that rutin content tended to decrease with the stage of maturity.

Isoquercetin (quercetin-3-O-glucoside) has been reported to have antimicrobial (Razavi et al., 2009) and antioxidant (Rogerio et al., 2007) effects. Onogi et al. (1993) detected four flavonol glycosides in mulberry leaves, with isoquercetin and astragalin as the major flavonoids. We found that the isoquercetin content of mulberry leaves ranged from 300.19 to $510.87 \mathrm{mg} 100 \mathrm{~g}^{-1} \mathrm{DM}$ (Table 1). The highest isoquercetin content was found during September in 'Plodovaja 3' (510.87 $\left.\mathrm{mg} 100 \mathrm{~g}^{-1} \mathrm{DM}\right)$. The amount of isoquercetin was found 194 mg $100 \mathrm{~g}^{-1} \mathrm{DM}$ by Katsube et al. (2006). Kim et al. (2014) found that the isoquercetin content in the leaves ranged from $466-753 \mathrm{mg} 100 \mathrm{~g}^{-1} \mathrm{DM}$. However, the isoquercetin contents varied greatly with the harvest time.

We quantitatively analysed the nicotiflorin contents of leaves from the two mulberry cultivars harvested over three

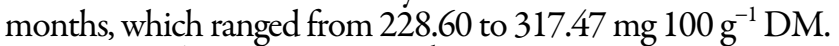

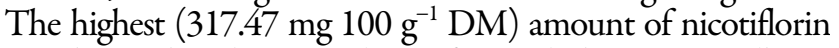
was detected in the young leaves from 'Plodovaja 3'. Mulberry leaves harvested in September accumulated the highest nicotiflorin content compared with other harvest times for 'Turchanka'.

Astragalin has also been reported to have antioxidant (Choi et al., 2013) and anti-inflammatory (Lee et al., 2011) effects. Astragalin is considered to be ubiquitous in the plant kingdom,

Table 1. Influence of the harvest time on the quantitative and qualitative flavonoid contents of mulberry leaves.

\begin{tabular}{|c|c|c|c|}
\hline \multirow{2}{*}{ Cultivar } & \multicolumn{3}{|c|}{ Harvest time } \\
\hline & July & August & September \\
\hline & \multicolumn{3}{|c|}{ Total flavonoid content $\left(\mathrm{mg} 100 \mathrm{~g}^{-1} \mathrm{DM}\right)$} \\
\hline 'Plodovaja 3' & $1471.92^{\mathrm{Aa}}$ & $1512.02^{\mathrm{Aa}}$ & $1493.26^{\mathrm{Aa}}$ \\
\hline \multirow[t]{2}{*}{ 'Turchanka' } & $1087.43^{\mathrm{Aa}}$ & $921.92^{\mathrm{Bb}}$ & $1128.89^{\mathrm{Ba}}$ \\
\hline & \multicolumn{3}{|c|}{ Rutin (mg $\left.100 \mathrm{~g}^{-1} \mathrm{DM}\right)$} \\
\hline 'Plodovaja 3' & $601.41^{\mathrm{Aa}}$ & $526.61^{\mathrm{Ab}}$ & $479.46^{\mathrm{Ab}}$ \\
\hline \multirow[t]{2}{*}{ 'Turchanka' } & $337.79^{\mathrm{Ba}}$ & $276.96^{\mathrm{Bb}}$ & $321.42^{\mathrm{Ba}}$ \\
\hline & \multicolumn{3}{|c|}{ Isoquercetin (mg $\left.100 \mathrm{~g}^{-1} \mathrm{DM}\right)$} \\
\hline 'Plodovaja 3' & $395.22^{\mathrm{Ab}}$ & $501.94^{\mathrm{Aa}}$ & $510.87^{\mathrm{Aa}}$ \\
\hline \multirow[t]{2}{*}{ 'Turchanka' } & $345.55^{\mathrm{Bb}}$ & $300.19^{\mathrm{Bc}}$ & $382.83^{\mathrm{Ba}}$ \\
\hline & \multicolumn{3}{|c|}{ Nicotiflorin (mg $\left.100 \mathrm{~g}^{-1} \mathrm{DM}\right)$} \\
\hline 'Plodovaja 3' & $317.47^{\mathrm{Aa}}$ & $263.29^{\mathrm{Ab}}$ & $242.47^{\mathrm{Ab}}$ \\
\hline \multirow[t]{2}{*}{ 'Turchanka' } & $241.84^{\mathrm{Bb}}$ & $228.60^{\mathrm{Bb}}$ & $264.77^{\mathrm{Aa}}$ \\
\hline & \multicolumn{3}{|c|}{ 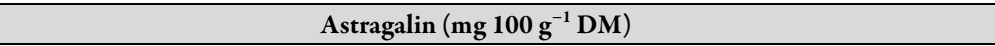 } \\
\hline 'Plodovaja 3' & $157.82^{\mathrm{Ac}}$ & $220.18^{\mathrm{Ab}}$ & $260.46^{\mathrm{Aa}}$ \\
\hline 'Turchanka' & $162.25^{\mathrm{Aa}}$ & $116.17^{\mathrm{Bb}}$ & $159.87^{\mathrm{Ba}}$ \\
\hline
\end{tabular}

Note: Different small letters (a, b, c) in the same row and capital letters (A, B, C) in the same column represent significant differences between harvest time and cultivar, respectively, at $p<0.05$. 
434

and some studies have shown that it is effective against allergic diseases (Kotani et al., 2000). We found that the astragalin contents were affected by the harvest month. The highest amount $\left(260.46 \mathrm{mg} 100 \mathrm{~g}^{-1} \mathrm{DM}\right)$ was found in mulberry leaves from 'Plodovaja 3' in September (Table 1). More astragalin accumulated in 'Turchanka' leaves harvested during July (162.25 mg $\left.100 \mathrm{~g} \mathrm{~g}^{-1} \mathrm{DM}\right)$ compared with other months. Zou et al. (2012) have reported that the astragalin was markedly affected by harvest month, with its concentration reaching the highest level in August in Southern China. Katsube et al. (2006) have indicated different studies, the amount of astragalin was low $\left(31 \mathrm{mg} 100 \mathrm{~g}^{-1} \mathrm{DM}\right)$. Other authors indicated that astragalin content ranged from 257-390 $\mathrm{mg} 100 \mathrm{~g}^{-1} \mathrm{DM}$ from various areas in Korea (Kim et al., 2014).

\section{Chlorogenic acid}

Chlorogenic acids are members of the phenolic acid, and this type of phytochemical is present in various plant parts. The abundance of this compound in mulberry leaves may depend on various factors, such as the cultivar, agricultural practices, environmental conditions, and harvest time (Zou et al., 2012). According to Memon et al. (2010), chlorogenic acid is the predominant phenolic acid in mulberry leaves, where its abundance ranges from $60.5 \%$ to $67.2 \%$ of the total phenolic acid content.

Our findings show that the chlorogenic acid contents in the leaves of the mulberry cultivars varied from 136.18 to $223.00 \mathrm{mg} 100 \mathrm{~g}^{-1} \mathrm{DM}$ (Fig. 1). The highest chlorogenic acid contents were found during July in 'Plodovaja 3' $(223.00 \mathrm{mg}$ $100 \mathrm{~g}^{-1} \mathrm{DM}$ ) and during September in 'Turchanka' (177.32 $\left.\mathrm{mg} 100 \mathrm{~g}^{-1} \mathrm{DM}\right)$. However, Zou et al. (2012) found that the chlorogenic acid contents in the leaves from six mulberry cultivars collected from April to October did not change significantly over seven months. In contrast, Lee and Choi (2012) found that the chlorogenic acid contents of the leaves from most mulberry cultivars decreased rapidly from May to September. The chlorogenic acid contents of 'Plodovaja 3' were significantly higher than those of 'Turchanka' in all months. Thus, considerable differences in chlorogenic acid content of mulberry leaves exist among mulberry cultivars. The cultivar differences had an impact on the chlorogenic acid contents. Other scientists have also confirmed its dependence on characteristics of a cultivar (Lee and Choi, 2012; Zou et al., 2012).

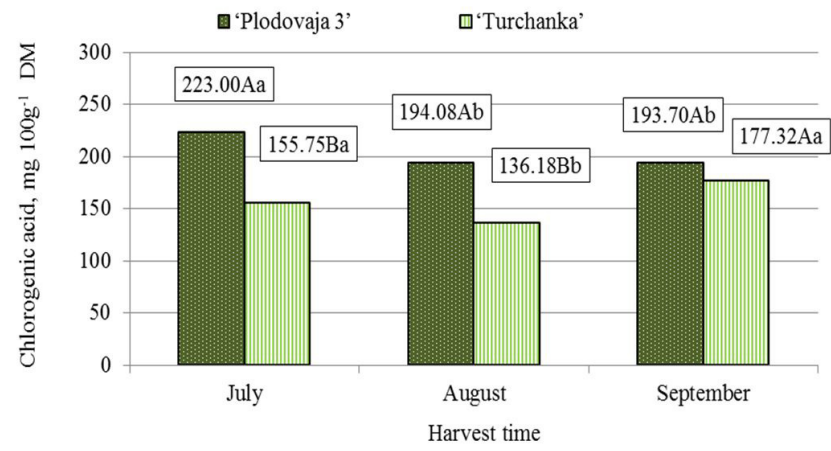

Fig. 1. Effects of the harvest time on the chlorogenic acid contents of mulberry leaves. Note: different small letters (a, b, c) represent significant differences between harvest time and capital letters (A, B, C) between cultivar, at $p<0.05$

\section{Antiradical activity according to the DPPH method}

The antioxidant activity depends on substances (e.g., phenolic compounds, flavonoids, and tannins) formed during secondary metabolism. Memon et al. (2010) reported that mulberry leaves exhibited highly variable antioxidant activity, ranging from 22.85-76.88 $\mu \mathrm{mol} 100 \mathrm{~g}^{-1}$ quercetin equivalents.

We found that the antiradical activities in the leaves from 'Plodovaja 3' and 'Turchanka' were significantly higher in September, there by supporting a previous report that the antioxidant activity increases gradually in mulberry leaves before declining in the leaf-fall stage (Kim, 2005). In September, the antiradical activities of 'Plodovaja 3' and 'Turchanka' were $16.50 \mu \mathrm{mol} \mathrm{TE} \mathrm{g}{ }^{-1} \mathrm{DM}$ and $15.34 \mu \mathrm{mol}$ $\mathrm{TE}^{-1} \mathrm{DM}$, respectively (Fig. 2). In both cultivars, the antiradical activity was lowest in August.

Our results indicate that 'Plodovaja 3' leaves had higher antiradical activities in all months. This higher antiradical activity may be associated with the larger amounts of chlorogenic acid in the leaves. Zou et al. (2012) showed that the cultivar and harvest month had significant effects on the antioxidant activity in mulberry leaves.

The correlation analysis indicated a very strong positive relationship between the antiradical activity according to the DPPH free radical scavenging method and the chlorogenic acid contents $(\mathrm{r}=0.887, p<0.05)$ and the isoquercetin contents $(r=0.848, p<0.05)$ (Table 2). Thus, we suggest that the antiradical activity of mulberry leaves depends on the contents of these compounds where the antiradical activity increases with their abundance in the leaves. ArabshahiDelouee and Urooj (2007), Zhang et al. (2013) indicated that the antioxidant activities of mulberry leaves were associated with the phenolic and/or flavonoid contents.

\section{Conclusions}

This study showed that the mulberry leaves from both cultivars were nutritionally rich. The highest total flavonoid contents were found in the leaves of 'Turchanka' during September and 'Plodovaja 3' during August. The main flavonoid was rutin, and the highest amount was determined in all cultivars during July. The isoquercetin, nicotiflorin, astragalin, and chlorogenic acid contents of white mulberry leaves depended on the harvest time. The highest antiradical activity, determined by the DPPH method, was found in the leaves from 'Plodovaja 3'. Our results may help to select the best cultivar and harvest month in order to produce better quality mulberry leaves.

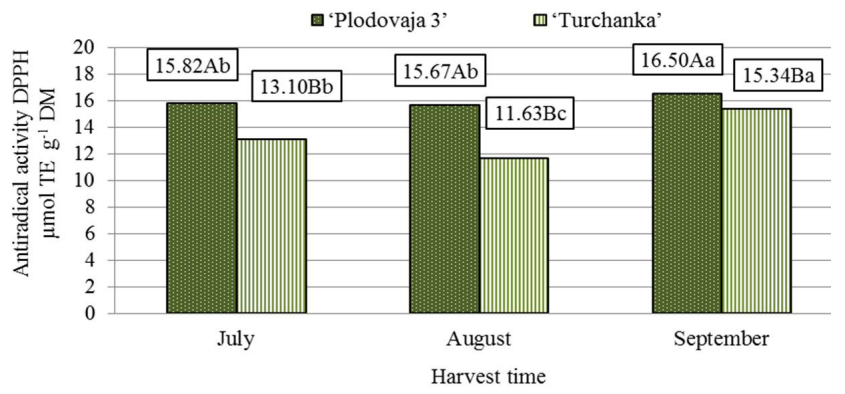

Fig. 2. Effects of harvest time on the antiradical activity determined by the DPPH method in mulberry leaves. Note: different small letters $(a, b, c)$ represent significant differences between harvest time and capital letters $(\mathrm{A}, \mathrm{B}, \mathrm{C})$ between cultivar, at $p<0.05$ 
Table 2. Correlation coefficients between the flavonoid contents (rutin, isoquercetin, nicotiflorin, and astragalin), chlorogenic acid contents, and antiradical activity (DPPH)

\begin{tabular}{|c|c|c|c|c|c|c|}
\hline & Chlorogenic acid & Rutin & Isoquercetin & Nicotiflorin & Astragalin & DPPH \\
\hline Chlorogenic acid & - & $0.929^{* *}$ & n.s. & $0.841^{*}$ & n.s. & $0.887^{*}$ \\
\hline Rutin & $0.929^{* *}$ & - & n.s. & n.s. & n.s. & n.s. \\
\hline Isoquercetin & n.s. & n.s. & - & n.s. & $0.953^{* *}$ & $0.848^{*}$ \\
\hline Nicotiflorin & $0.841^{*}$ & n.s. & n.s. & - & n.s. & n.s. \\
\hline Astragalin & n.s. & n.s. & $0.953^{* *}$ & n.s. & - & n.s. \\
\hline DPPH & $0.887^{*}$ & n.s. & $0.848^{*}$ & n.s. & n.s. & - \\
\hline
\end{tabular}

${ }^{* *} p<0.01,{ }^{*} p<0.05$, n.s.: no significant difference

\section{References}

Adeduntan SA, Oyerinde AS (2009). Evaluation of chemical and antinutritional characteristics of obeche (Triplochition scleroxylon scleroxylon) and some mulberry (Morus alba) leaves. International Journal of Biological and Chemical Sciences 3:681-687.

Arabshahi-Delouee S, Urooj A (2007). Antioxidant properties of various solvent extracts of mulberry (Morus indica L.) leaves. Food Chemistry 102:1233-1240.

Arct J, Pytkowska K (2008). Flavonoids as components of biologically active cosmeceuticals. Clinics in Dermatology 26:347-357.

Butt MS, Nazir A, Sultan TM, Schoën K (2008). Morus alba L. nature's functional tonic. Trends in Food Science \& Technology 19:505-512.

Chan EW, Lye PY, Wong SK (2016). Phytochemistry, pharmacology, and clinical trials of Morus alba. Chinese Journal of Natural Medicines 14(1):17-30.

Chauhan S, Devi U, Kumar VR, Kumar V, Anwar F, Kaithwas G (2015). Dual inhibition of arachidonic acid pathway by mulberry leaf extract. Inflammopharmacology 23:65-70.

Choi J, KangHJ, Kim SZ, Kwon TO, JeongSI,JangSI (2013). Antioxidant effect of astragalin isolated from the leaves of Morus alba L. against free radical-induced oxidative hemolysis of human red blood cells. Archives of Pharmacal Research 36:912-917.

Choi JS, Kang SW, Li J, Kim JL, Bae JY, Kim DS, Shin SY, Jun JG, Wang MH, Kang YH (2009). Blockade of oxidized LDL-triggered endothelial apoptosis by quercetin and rutin through differential signaling pathways involving JAK2. Journal of Agricultural and Food Chemistry 57:2079-2086.

Guan LP, Zheng GH, Jian ZY, Quan C (2006). Determination of rutoside in mulberry leaves in different resources and different collect times by RP-HPLC (in Chinese). Lishizhen Medicine And Materia Medica Research 17:356-357.

Jeszka-Skowron M, Flaczyk E, Podgórski T (2017). In vitro and in vivo analyses of Morus alba Polish var. wielkolistna zolwinska leaf ethanolwater extract-antioxidant and hypocholesterolemic activities in hyperlipideamic rats. European Journal of Lipid Science and Technology 119, e201600514. doi:10.1002/ejt.201600514.

Jia Z, Tang M, Wu J (1999). The determination of flavonoid contents in mulberry and their scavenging effects on superoxide radicals. Food Chemistry 64:555-559.

Katsube T, Imawaka N, Kawano Y, Yamazaki Y, Shiwaku K, Yamane Y (2006). Antioxidant flavonol gycosides in mulberry (Morus alba L.) leaves isolated based on LDL antioxidant activity. Food Chemistry 97:25-31.

Kim DS, Kang YM, Jin WY, Sung YY, Choi G, and Kim HK (2014). Antioxidant activities and polyphenol content of Morus alba leat extracts collected from varying regions. Biomedical Reports 2:675-680.

$\mathrm{Kim} \mathrm{HB}$ (2005). Anti-oxidative capacity analysis of water-soluble substances according to varieties and maturity stages in mulberry leaves and fruits. Korean Journal Seric Science 47:62-67.

Kobayashi Y, Miyazawa M,Araki M, Kamei A,AbeK,Hiroi T, ... Kojima T (2015). Effects ofMorus alba L(Mulberry) leaf extract in hypercholesterolemic mice on suppression of cholesterol synthesis. Journal of Pharmacognosy and Natural Products 2(113), doi:10.4172/2472-0992.1000113.

Kotani M, Matsumoto M, Fujita A, Higa S, Wang W, Suemura M, Kishimoto T, Tanaka T (2000). Persimmon leaf extract and astragaling inhibit the development of dermatitis and IgE elevation in NC/Nga mice.Journal of Allergy and Clinical Immunology 106:159-66.

Lee CY, Sim SM, Cheng HM (2007). Systemic absorption of antioxidants from mulberry (Morus alba $\mathrm{L}$ ) leaf extracts using an in situ rat intestinal preparation. Nutrition Research 27:492-497.

Lee HB, Kim EK, Park SJ, Bang SG, Kim TG, Chung DW (2011). Isolation and anti-inflammatory effect of astragalin synthesized by enzymatic hydrolysis of tea seed extract. Journal of the Science of Food and Agriculture 91:2315-2321.

Lee WJ, Choi SW (2012). Quantitative changes of polyphenolic compounds in mulberry (Morus alba L.) leaves in relation to varieties, harvest period, and heat processing. Preventive Nutrition and Food Science 17:280-285.

Łochyńska M (2015). Energy and nutritional properties of the white mulberry (Morus alba 1.). Journal of Agricultural Science and Technology 5:709-716.

Matei A, Tanase DB, Diaconescu C, Constatinescu M, Dolis M (2006). Contributions to the study of the leaf protein value in different mulberry varieties. Archiva Zootechnica 9:153-157.

Matsuoka T, Kimura T, Muraoka N (1994). Research of the available constituents from mulberry tree. Tohoku Journal of Agricultural Research 47:361-362.

Memon AA, Memon N, Luthria DL, Bhanger MI, Pitafi AA (2010). Phenolic acids profiling and antioxidant potential of mulberry (Morus laevigata W., Morus nigra L., Morus alba L.) leaves and fruits grown in Pakistan. Polish Journal of Food and Nutrition Sciences 60:25-32.

Onogi A, Osawa K, Yasuda H, Sakai A, Morita H, Itokawa H (1993). 
436

Flavonol gycosides from the leaves of Morus alba L. Shoyakugaku Zasshi 47:423-425.

Paredes-López O, Cervantes-Ceja ML, Vigna-Pérez M, Hernández-Pérez T (2010). Berries: improving human health and healthy aging, and promoting quality life - A review. Plant Foods for Human Nutrition 65:299-308.

Parejo I, Viladomat F, Bastida J, \& Codina C (2004). Development and validation of a high-performance liquid chromatographic method for the analysis of antioxidative phenolic compounds in fennel using a narrow bore reversed phase C18 column. Analytica Chimica Acta 512(2):271-280.

Radojkovic MM,ZekovicZP, VidovicSS, Kocar DD, Maskovic PZ (2012). Free radical scavenging activity, total phenolic and flavonoid contents of mulberry (Morus spp. L., Moraceae) extracts. Hemijska Industrija 66:547-552.

Razavi SM, Zahri S, Zarrini G, Nazemiyeh H, Mohammadi S (2009). Biological activity of quercetin-3-O-glucoside, a known plant flavonoid. Bioorganicheskaia Khimiia 35:414-416.

Rogerio AP, Kanashiro A, Fontanari C, da Silva EV, Lucisano-Valim YM, Soares EG, Faccioli LH (2007). Anti-inflammatory activity of quercetin and isoquercitrin in experimental murine allergic asthma. Inflammation Research 56:402-408.

Srivastava S, Kapoor R, Thathola A, Srivastava RP (2006). Nutritional quality of leaves of some genotypes of mulberry (Morus alba). International Journal of Food Sciences and Nutrition 57:305-313.

Sugiyama M, Katsube T, Koyama A, Itamura H (2016a). Effect of solar radiation on the functional components of mulberry (Morus alba L.) leaves. Journal of the Science of Food and Agriculture 96:3915-3921.
Sugiyama M, Takahashi M, Katsube T, Koyama A, Itamura H (2016b). Effect of nitrogen application amount on the functional components of mulberry (Morus alba L.) leaves. Journal of Agricultural and Food Chemistry 64:6923-6929.

Sugiyama M, Katsube T, Koyama A, Itamura H (2017). Seasonal changes in functional component contents in mulberry (Morus alba L.) leaves. The Horticulture Journal doi: 10.2503/hortj.OKD-053.

Sývacý A, Semen M (2004). Seasonal changes in antioxidant activity, total phenolic and anthocyanin constituent in the stems of two Morus species (Morus alba L. and Morus nigra L.). Plant Growth Regulation 44:251256.

Yen GC, Chen HY (1995). Antioxidant activity of various tea extracts in relation to their antimutagenicity. Journal of Agricultural and Food Chemistry 46:849-854.

Zhang LL, Wang YM, Xu M, Wu DM, Chen JH, Yan XP (2013). Antioxidant activity, phenol and flavonoid contents of fourteen mulberryvarieties leaves. Advanced Materials Research 781:14541459.

Zhishen J, Mengcheng T, Jianming W (1999). The determination of flavonoid contents in mulberry and their scavenging effects on superoxide radicals. Food Chemistry 64:555-559.

Zou Y, Liao S, Shen W, Liu F, Tang C, Chen CYO, Sun Y (2012). Phenolics and antioxidant activity of mulberry leaves depend on cultivar and harvest month in southern China. International Journal of MolecularSciences 13:16544-16553. 